\title{
A NIDIFICAÇÃO DE PIONUS MAXIMILIANI (KUHL) E ARA MARACANA (VIEILLOT) EM GÁLIA SÃO PAULO, BRASIL (AVES, PSITTACIDAE)
}

\author{
Cory T. de Carvalho ${ }^{1}$ \\ José Carvalho ${ }^{1}$
}

\begin{abstract}
NESTING OF PIONUS MAXIMILIANI (KUHL) AND ARA MARACANA (VIEILLOT) IN GÁLIA, SÃO PAULO, BRAZIL. Nests of the "Scaly-headed parrot" and "Illiger's macaw" - Pionus maximiliani (Kuhl, 1820) and Ara maracana (Vieillot, 1816) - found at the Ecological Station in Gália, São Paulo with clutches in 26-VII-90 and 20-IX-90, both containing four white rounded and at one end slightly pointed eggs, measuring $33.4 \times 30.0 \mathrm{~mm}$ and $33.0 \times 28.0 \mathrm{~mm}$ each respectively, are being reported on. The incubation in the "Scaly-headed parrot" lasted for 26 days, the stay of the young in the nest cavity for about 50 days and only one adult was seen incubating, while in "Illiger's or Blue-winged macaw" both parents used to stay in the nest.
\end{abstract}

KEY WORDS. P. maximiliani, A. maracana, nests, clutches, habits

Até o presente, são relativamente poucas as informações sobre a bionomia de grande número de nossas aves e mais ainda de interessados nesse campo de atividades. A parte sistemática é básica, seguindo-se naturalmente informes biológicos de cada espécies. Não só de espécies, mas até famílias inteiras carecem ou são escassamente conhecidas quanto à nidificação, ovos e referências aos hábitos.

EULER (1867/68) foi o iniciador aqui no Brasil desse tipo de trabalho, ao publicar no Journal für Ornithologie de Cabanis sua "Contribuição para a história natural das aves do Brasil", a qual foi traduzida e ampliada com modificações por IHERING (1900) para Cantagalo e Nova Friburgo, Rio de Janeiro. Estes trabalhos comentam uns 90 anos atrás, que em "uma família tão em evidência pouco se conhece de seus ovos" (p. 85).

O ninho, como um padrão na família, é um oco aproveitado em forma de cavidade nas árvores grossas, com madeira triturada no fundo onde eles põem seus ovos e criam seus filhotes. Os ovos são brancos, sem desenhos, de forma esférica-alongada nas extremidades ou numa só e, uns poucos são conhecidos. Talvez mais em cativeiro do que na mata.

Em seqüência, PINTO (1953) com o farto material colhido por C. Estevão em Belém, Pará e arredores, fez uma série de comentários como: época de nidificação, número de posturas, quantidade de ovos em cada uma delas, o papel dos sexos na incubação e criação dos filhotes, forma dos ninhos e também

1) Instituto Florestal do Estado de São Paulo, Caixa Postal 26, 18780-000 Manduri, São Paulo, Brasil. 
reclama da falta de informações no grupo-família.

SICK (1984/85) condensa em seu trabalho o que foi publicado e acrescenta algumas outras informações, com o pouco que existe de conhecimentos de campo no assunto. Entretanto, os ninhos são bem conhecidos e fiscalizados por alguns mateiros que deles apenas, retiram os filhotes em tenra idade para criação e venda.

Recentemente em Gália, São Paulo, na Estação Ecológica $\left(22^{\circ} 23^{\prime} \mathrm{S}\right.$ e $49^{\circ} 41^{\prime} \mathrm{W}$ ) durante os nossos trablhos com "micos" - Leontopithecus chrysopygus (Mikán, 1823) - demos com a constante vigília de casais de "maitaca-bronze" e de "ararinha" em certas árvores com buracos e lá, posteriormente instalaram seus ninhos. Nos intervalos de tempo disponível, procuramos obter informes e sobrepujar as dificuldades existentes nesse tipo de trabalho: chegar ao oco, acompanhar a postura, incubação e a criação dos filhotes.

\section{RESULTADOS}

Em meados de julho, num oco ou cavidade no tronco de um "Pau Jacaré" (Piptadenia gonoacantha Mart.) aos 5,30m de altura, câmara uns $0,50 \mathrm{~m}$ abaixo e 1,32m de diâmetro DAP, árvore situada na borda da estrada, avistamos com bastante insitência a vigília de uma "maitaca" - Pionus maximiliani (Kuhl, 1820)durante nossa passagem, observando em silêncio com parte do corpo ou um terço dele para fora, o que despertou curiosidade. Subimos e através de uma fenda aberta verificamos a presença de um ovo na cavidade ou câmara aos 26-VII-90 às onze horas.

Posteriormente com luz e ampliação da abertura, verificamos aos 21-VIII-90 às nove horas, a existência de quatro ovos, possivelmente postos diariamente e incubados desde o primeiro deles. Os ovos são brancos, lisos com um dos pólos mais arrendodados e o outro ligeiramente afilado, medindo um deles $31,4 \times 35,0 \mathrm{~mm}(34,95 \mathrm{~mm})$. No dia seguinte (22-VIII-90) nascia o primeiro filhote e dois outros ovos bicados, perfazendo a incubação 26 dias. As medidas e o tempo de incubação se aproximam dos dados já conhecidos de outras espécies, isto é, $32,0 \times 28,0 \mathrm{~mm}$ para Pionus menstruus (Linnaeus, 1766) de Nehrkorn, p.176 (in IHERING, op. cit.); 34,0×27,5mm e 35,0×27mm para Pionus fuscus (P.L.S. Müller, 1776) (PINTO, 1953), com 22 ou 23 dias de incubação em Pionites Heine, 1890.

As cascas dos ovos são deixadas dentro da câmara, junto aos filhotes e ovos com alguns sujos e cavacos; os filhotes são enegrecidos, com pele negra e penugem cinza, cera, bico e pés esbranquiçados, e até uns três dias, olhos fechados. Somente vimos uma "maitaca" no ninho, a outra ave sempre permanecia nas proximidades (em torno de $40 \mathrm{~m}$ de distância) e, quando deixava o ninho em silêncio, a outra a acompanhava imediatamente em vôo baixo.

Não observamos troca imediata do par nos trabalhos de incubação, nem o suprimento de alimentos ao que executava a tarefa, embora conste na literatura. A chegada é cuidadosa, com um intervalo de uns 15 minutos entre saídas e chegadas, com um pouso antes na proximidade do oco e, vez por outra, sobe 
até a entrada dele com ajuda do bico, trepando.

Aos 06-X-90 um filhote pesava 272,5g, já bem emplumado como adulto e capaz de dar pequenos vôos. Em 26-X-90 ao voltar ao local os quatro filhotes já haviam deixado a câmara-ninho, perfazendo a permanência uns cinqüenta dias se não molestados.

Em outra árvore, mais para o interior da mata, em torno de $60 \mathrm{~m}$ adiante e na mesma estrada, em uma "Guaraiúva" (Savia dyctiocarpa Mill.) com oco aos $14 \mathrm{~m}$ de altura e diâmetro de 1,70m DAP, um casal de "ararinhas" (Ara maracana Viell.) também se instalou, o que parece ser comum nos ocos usados pelos "micos" nessa época do ano, e aí nidificou aos 20-09-90. A entrada do oco-ninho e a câmara de incubação ficavam uns 14 metros acima do solo, em árvore isolada, emergente e com oco mais amplo para cima, com saídas.

Nessa data (20-IX-90) vimos um filhote nascido e mais três ovos, bem como uma pequena cobra morta no ninho (não peçonhenta, já em decomposição), às $16: 15$ horas. $\mathrm{O}$ ovo media $33,0 \times 28,0 \mathrm{~mm}$ e pesava $30 \mathrm{~g}$ no fim do período de incubação. Aos $26-X-90$ havia apenas um filhote já crescido no ninho, razoavelmente emplumado e nenhum vestígio das cascas e ovos na cavidade, como na espécie anterior. Também vimos que a ave adulta ainda dormia na cavidade-ninho. A câmara distava da saída do oco ou buraco no tronco da árvore, uns $40 \mathrm{~cm}$ e da bifurcação, um metro aproximadamente.

Aí, sempre vimos o casal no oco, um em uma abertura lateral ou buraco superior à câmara e o outro na parte mais superior em meio a folhagens e da bifurcação do tronco. Saiam um após ao outro, voando e gritando ou pousavam em árvores nas proximidades com visão ampla, vocalizando.

\section{REFERÊNCIAS BIBLIOGRÁFICAS}

EULER, C. 1867/68. Descrição de ninhos e ovos das aves do Brasil, 1900. Revta Mus. Paul., São Paulo, 4: 9-148.

IHERING, H. VON. 1900. Catálogo crítico-comparativo dos ninhos e ovos das aves do Brasil. Revta Mus. Paul., São Paulo, 4: 191-300.

PINTO, O. 1953. Sobre a coleção Carlos Estevão de peles, ninhos e ovos das aves de Belém (Pará). Pap. Av. Dep. Zool., São Paulo, 11 (13): 111-222.

SICK, H. 1984/85. Ornitologia Brasileira. Uma introdução. Brasília, Universidade de Brasília, vol. 1 e 2, $1^{\mathrm{a}}$ ed., 827p.

Recebido em 22.III.1993; aceito em 04.X.1993. 